\title{
pharmaceuticals
}

ISSN 1424-8247

www.mdpi.com/journal/pharmaceuticals

Review

\section{Atypical Antipsychotics and Other Therapeutic Options for Treatment of Resistant Major Depressive Disorder}

\author{
Rubo J. Seo, Holly MacPherson and Allan H. Young * \\ Institute of Mental Health, Department of Psychiatry, University of British Columbia, 5950 University \\ Blvd. Vancouver, BC V6T 1Z3, Canada; E-Mails: donyseo@hotmail.com (R.J.S.) ; \\ hollymacpherson@gmail.com (H.M.); \\ * Author to whom correspondence should be addressed; E-Mail: allan.young@ubc.ca; \\ Tel.: +1-604-827-3685; Fax: +1-604-827-3373.
}

Received: 1 November 2010; in revised form: 24 November 2010 / Accepted: 2 December 2010/ Published: 3 December 2010

\begin{abstract}
Antidepressant therapies, such as selective serotonin reuptake inhibitors (SSRIs), are current first-line treatments for Major Depressive Disorder. However, over $50 \%$ of treated patients show an inadequate response to initial antidepressant therapy. If the therapeutic outcomes from two antidepressant therapies are suboptimal, potentially resulting in Treatment Resistant Depression, subsequent strategies include switching to another antidepressant or augmenting treatment by combining with other agents. When combined with SSRIs, atypical antipsychotics have supplementary action on dopaminergic and noradrenergic systems. Studies on combined treatment with atypical antipsychotics have shown significantly increased remission rates, shortened response times, and favorable side effects. Augmentation of antidepressants with atypical antipsychotics is now an acceptable treatment strategy which leads to increased remission rates and better outcomes for patients.
\end{abstract}

Keywords: treatment resistant disorder; major depressive disorder; augmentation; atypical antipsychotic; typical antipsychotic; antidepressant; selective serotonin reuptake inhibitor; electroconvulsive therapy 


\section{Introduction}

Major Depressive Disorder (MDD) is the third leading cause of disease burden worldwide [1] and will affect between 13-16\% of people during the course of their lifetime [2,3]. Characterized by symptoms which include low mood, along with low self-esteem, and/or loss of interest or pleasure in normally enjoyable activities [4], the impact of depression can be severe. It causes significant impairment, poor social and occupational functioning, and is associated with high rates of psychiatric comorbidity, increased rates of physical health problems and raised mortality. Of those hospitalized with severe depression, approximately $16 \%$ eventually commit suicide [5]. Episodes of major depression can occur within the context of major depressive disorder or bipolar disorder [4] and treatment options will not necessarily be the same for both. However, this review focuses on depression as part of MDD.

\subsection{Potential Treatments for MDD}

Antidepressant medications have been in use for the treatment of MDD since the 1950s. Tricyclic antidepressants (TCAs) and monoamine oxidase inhibitors (MAOIs) were the first modern pharmacotherapies used for depression but have been less used lately because they are associated with problematic side effects and drug interactions; TCAs are associated with anticholinergic (dry mouth, blurred vision, constipation), antihistaminergic (sedation, carbohydrate craving, increased appetite), and anti- $\alpha$-1-adrenergic (orthostatic hypotension) side effects, whereas MAOIs are associated with insomnia, sedation, and orthostatic hypotension [6]. Derivative compounds such as norepinephrine reuptake inhibitors (NERIs) and the serotonin-norepinephrine reuptake inhibitors (SNRIs) as well as other selective antidepressants like the noradrenaline-dopamine reuptake inhibitors (NDRIs; bupropion) and tetracyclic antidepressants (TeCA; mirtazapine) were introduced from the 1970s onwards and are believed to be more tolerable than TCAs and MAOIs. In particular, serotonin reuptake inhibitors (SSRIs) are believed to have good tolerability profiles and accounted for more than half of all antidepressant prescriptions in 2006 [7,8]. The naturally occurring molecule, S-adenosyl-Lmethionine (SAMe), has also been used as an alternate pharmacologic approach and has shown antidepressant efficacy comparable to TCAs with minimal side effect profiles. In addition, psychosocial therapy should be added to ongoing pharmacotherapy to maximize improvement in remission of symptoms as well as facilitating patients to regain normal everyday functioning.

\subsection{Treatment Resistant Depression}

Despite the plethora of available antidepressants with differing modes of action, only modest differences in efficacy have been found. According to a Sequenced Treatment Alternatives to Relieve Depression $\left(\mathrm{STAR}^{*} \mathrm{D}\right)$ report, only one-third of patients receiving initial antidepressant therapy achieve remission [9]. It has been found that $29-46 \%$ of depressed patients on SSRIs remain unresponsive to treatment [10]. In addition, the STAR*D study also reported that after each failed pharmacotherapy trial, remission rates decline; after two or three failed treatment trials, subsequent remission rates averaged less than $15 \%$ [9]. 
Patients who have partial or no response to pharmacotherapy may be characterized as having treatment resistant depression (TRD). Numerous definitions and stages of treatment resistance have been suggested. TRD has been described clinically along a continuum, from first episode patients failing single antidepressant treatments to chronic patients failing multiple combined and/or augmented therapies [11]. Thase and Rush have proposed five stages of TRD, varying from an unsuccessful trial of one antidepressant with adequate dose and duration (Stage I) to failure of three to four classes of antidepressants plus ECT (Stage V) [12]. General consensus defines TRD as failure to respond to two different prospective trials of antidepressants of adequate dose and duration.

The clinician's initial response to a potential case of TRD should include a re-evaluation of the diagnosis, an examination for psychiatric comorbidities that may hinder therapeutic response, and verification that the patient is complying with treatment. For those suffering from treatment resistant depression, in which the therapeutic response to treatment has plateaued or has remained unchanged within 3 weeks, the first step for many would be to increase the dose of the initial SSRI. If there is no significant response to the dose increase within 2-4 weeks, a clinician should consider switching to another SSRI or to another pharmacological class of antidepressant. Switching pharmacotherapy is suitable for those patients who either show no response to initial treatment, show only an inadequate response to initial treatment even after an increase in dose, or their response was outweighed by side effects. For the partial responder whose pharmacotherapy has not been restricted by side effects, augmentation, i.e., the utilization of adjunctive medication to enhance the action of the initial antidepressant medication is particularly useful. Pharmacological profiles of the augmentation agent must be carefully accounted for as it may aggravate existing side effects through, for instance, drugdrug interactions. Thus, clinicians must choose the augmentation agent with caution and use of symptom characteristics (both illness and side effects) might be used as a guide [13].

\subsection{Pharmacologic Profile of Depression}

The symptoms that characterize MDD are presumed to be associated with brain monoaminergic neuronal dysfunction. The role of serotonin and norepinephrine in the actions of antidepressants is well documented. Yet, because many depressed patients do not respond to SSRIs, NERIs, or combined agents, it is likely that other biochemical factors are involved. Recently, deficits in dopaminergic activity have been found in patients with TRD [14], suggesting that the pathogenesis of this variant of depression may reflect disturbances in all three neurotransmitter systems [15]. A large number of other neurotransmitters, from glutamate to neuropeptides, may be involved but are beyond the limited scope of the review.

\section{Augmentation Therapy}

All the published studies report that many patients with MDD commonly fail the first line antidepressant treatment. The general concensus approach to such cases are $2^{\text {nd }}, 3^{\text {rd }}$, and even $4^{\text {th }}$ line of treatment in an attempt to achieve full remission of symptoms [16]. Considering that approximately $70 \%$ of patients do not remit through an adequate course of first antidepressant treatment $[9,17,18]$, alternatives such as adding an effective second agent with improved safety and tolerability profiles to an ongoing antidepressant medication, referred to as augmentation therapy, can avoid patients from 
unnecessary switching between antidepressants which may jeopardize the remission rates and even aggravate existing side effects as suggested in the STAR*D study [9].

\subsection{Augmentation Agents}

Augmentation therapy is generally recommended to patients who have shown either treatmentresistant or insufficient response to an antidepressant regimen. The possible augmenting agents, which include lithium, triidothyronine (T3), benzodiazepines, S-adenosyl-L-methionine carbamazpine, valproic acid, buspirone, psychostimulants, typical antipsychotics and atypical antipsychotics, have been reported to improve clinical efficacy by treating residual symptoms $[19,20]$ and broaden the treatment's neurochemical profile by adding complementary pharmacodynamic action [21,22]. A common trial design is for the depressed patient to be first treated with an open-label antidepressant monotherapy for 6 to 8 weeks. Patients who show inadequate response are then randomized either to the second agent of interest or placebo [16]. According to a meta-analysis of 10 randomized-controlled trials, remission rates for the augmentation group were significantly superior when compared to the placebo groups $(p<0.0001)$ [23]. However, possible adverse effects involved with combining two medications must be considered when choosing for the right augmentation agent as it may potentiate already existing adverse effects, or alter the drug levels in plasma concentration. For instance, it is now generally understood that the transport of drugs from the intestine to the blood and from the periphery to the brain is facilitated by not only passive diffusional processes but also via the membrane protein P-glycoprotein (P450), a member of the adenosine triphosphate-binding cassette superfamily of transport-proteins, which transports antipsychotics such as risperidone through the gastrointestinal tract and the blood brain barrier. Depending on the nature of such substrates, it may induce or inhibit the action of P450 and likely to increase or decrease, respectively, the transport of the antidepressant drugs into the brain. [24]. Physicians must consider this notion in order to maintain the plasma drug levels in the therapeutically optimal range.

\subsection{Lithium Augmentation}

Lithium augmentation of patients with treatment resistant major depressive disorder was based on preclinical data that showed a positive association between lithium levels and presynaptic formation, storage, and release of serotonin in rats. Lithium augmentation, which is postulated to synergistically increase serotonergic action of antidepressants on brain 5-HT pathways [25], was first reported to augment patients with partial or absent response to T3 in 1981 and subsequently became a gold standard to treat patients with treatment resistant major depressive illness [26,27]. As one of the best documented approaches in TRD patients with existing TCA treatment, lithium augmentation has shown antidepressant efficacy and relative safety in both open and controlled studies [26,28,29]. The safety profiles of lithium augmentation in ongoing TCA therapy was supported by Schweitzer et al.'s work, showing that there were no serious or accentuation of adverse effects due to combination of two agents: anticholinergic and cardiovascular complications, nausea, diarrhea, abdominal pain, muscle weakness, and fine tremor from the lithium augmentation [30]. Also, no serious adverse effects were reported concerning lithium augmentation of MAOI therapy. For instance, reported risks for hypertensive crises due to the lithium augmentation were not higher than when MAOIs were used as a 
monotherapy. Further double-blind, randomized, placebo-controlled trials showed that fluoxetine and citalopram combination with lithium showed superior response without any indications of accentuation or aggravation of adverse effects compared to placebo [31,32]. However, caution must be present when augmenting SSRIs with lithium for both agents increase serotonin neurotransmission via different mechanisms and may potentiate serotonin syndrome marked by confusion, restlessness, myoclonus, hyperreflexia, diaphoresis, shivering, tremor, hypomania, diarrhea, and possibly death [33]. There have been two reported cases that therapeutical interactions between lithium and fluoxetine resulted in mania and hypomania [34].

\subsection{Triiodothyronine (T3) Augmentation}

Adjunctive T3 therapy is one of the most widely studied augmentation methods [20]. A direct comparison between lithium and triiodothyronine (T3) augmentation of TCA, indicated both to be equivalently effective and more effective than placebo [35]. While no significant differences were reported between these agents, the group augmented with T3 showed tendencies to greater numbers of responders and remitters, greater decreases in Hamilton Rating Scale for Depression (HAM-D) and Quick Inventory of Depressive Symptomatology (Self Report; QIDS-SR) scores, and greater tolerability to treatment. T3 not only may hold a slight advantage over lithium in efficacy and tolerability but also is easier to use and there is no need for blood monitoring [20]. Stein et al. supports the advantage of T3 over lithium augmentation of imipramine by showing enhanced and accelerated recovery with no association with aggravations of the attendant adverse effects [36]. The possible common adverse effects (drowsiness, dizziness, dry mouth, tremor, anxiety, cardiotoxicity, agitation, and insomnia) were all found to be mild or absent [37]. T3 augmentation of patients with treatment resistant major depressive disorder to phenelzine (MAOIs) also showed clinical improvement with no significant adverse effects [38,39].

\subsection{Benzodiazepine Augmentation}

According to a recent Cochrane Review, benzodiazepine augmentation with antidepressants may be beneficial for the treatment of depression. It was found that compared to antidepressant treatment alone, adjunctive benzodiazepines decrease drop outs from treatment as well as increasing short-term response up to four weeks. However, these potential benefits should be weighed against possible complications related to benzodiazepine augmentation, such as the development of dependence, a decline in the drug's effect over time, as well as an increase in "accident proneness" [40].

\subsection{S-Adenosyl-L-Methionine (SAMe) Augmentation}

SAMe is a naturally occurring molecule and has been commercially available in Europe since the late 1970s and as an over-the-counter dietary supplement in the United States since 1999. It has shown an antidepressant efficacy that is superior to placebo and equivalent to the effects of TCAs in a metaanalysis of randomized, double-blind, placebo- or TCA-controlled monotherapy trials [6]. In addition, a positive correlation between the increase of SAMe levels in the cerebrospinal fluid and the improvement in depressive symptoms have been observed [41]. Moreover, an examination of SAMe as 
an augmentation treatment of SSRIs in patients with treatment resistant major depressive disorder supported its potential efficacy, tolerability and safety [42]. According to the results, SAMe-treated patients and placebo-treated patients showed respective response rates of $36.1 \%$ and $17.6 \%$, remission rates of $25.8 \%$ and $11.7 \%$, and discontinuation rates due to intolerance of $5.1 \%$ and $8.8 \%$, respectively. There was no significant difference in adverse events between these two groups. The suggestive, yet preliminary, evidence of SAMe as an effective antidepressant in patients with treatment resistant major depressive disorder warrants confirmation in future studies so that SAMe might be recommended as a novel augmentation agent to the antidepressant therapy armamentarium.

\subsection{Other Types of Augmentation}

There have been a few case studies that showed marked improvement in patients with TRD after the addition of carbamazepine to TCAs [43], valproic acid to SSRIs [44] and buspirone to SSRIs [45,46] All the adverse effects reported in these studies were minimal or mild. However, augmenting with these agents (carbamazepine, valproic acid, and buspirone) carries the caveat that they are P450 inducers, inhibitors, and partial 5- $\mathrm{HT}_{1 \mathrm{~A}}$ agonists, repectively. Since these agents lack a body of supporting evidence for their use in TRD, physicians must carefully choose these methods as carbamazepine may lower the TCA levels whereas valproic acid may increase the serotonin levels in the brain. Buspirone may potentiate the SSRI side effects such as sexual dysfunction $[45,46]$. Overall, there were no discrepancies reported for these agents in terms of effectiveness and tolerability between genders; however, the usefulness of such agents in the elderly may be limited by dosing and pharmacological issues [47]. Psychostimulants may pose potential treatment for TRD as examined in case reports and open-label studies [48,49]; however, no double-blind, placebo-controlled trials have been conducted [50].

\subsection{Typical Antipsychotic Augmentation}

Typical antipsychotics, such as haloperidol and chlorpromazine, have had a long history in depression treatment. Use of these conventional antipsychotics, however, have waned due to their association with increased risk of extrapyramidal symptoms (EPS) including parkinsonism, dystonia, akathisia, and tardive dyskinesia [51], as well as torsades des pointes and sudden cardiac death [52]. Increasingly, augmentation strategies with atypical antipsychotics, which have lower reported incidences of EPS than typical agents, have gained prominence for the treatment of TRD. Dopamine $\mathrm{D}_{2}$ receptors, the principal brain target of antipsychotics, have been found to be involved in eliciting EPS. Typical antipsychotics have a tighter binding affinity at $\mathrm{D}_{2}$ receptor than dopamine itself and have a lower dissociation time course than dopamine. Conversely, atypical agents have a weaker binding affinity at $\mathrm{D}_{2}$ receptors and have a higher dissociation time course than dopamine. Thus, atypical agents transiently occupy the $\mathrm{D}_{2}$ receptors and then rapidly dissociate, allowing for normal dopamine neurotransmission. For effective antipsychotic action, the occupancy is reported to be approximately $65 \%$ at $\mathrm{D}_{2}$ receptor. However, EPS induction occurs when occupancy of $\mathrm{D}_{2}$ receptors by an antipsychotic is greater than $80 \%$ [53]. 


\section{Atypical Antipsychotic Augmentation Treatments}

For treatment-resistant patients, evidence suggests that augmentation treatment with atypical antipsychotics may have better treatment efficacy, safety and tolerability profiles than some other commonly used TRD treatments. Randomized controlled trials, although as yet limited, have failed to demonstrate clear cut evidence for one atypical agent over another [11,54-57].

\subsection{Aripiprazole Augmentation}

The use of aripiprazole may be efficacious in treating depressive symptoms in patients with schizophrenia [58] and bipolar disorder [59]. Aripiprazole's pharmacological action may be due to its partial agonist activity at the $\mathrm{D}_{2}, \mathrm{D}_{3}$ and $5-\mathrm{HT}_{1 \mathrm{~A}}$ receptors as well as its antagonistic effect at 5- $\mathrm{HT}_{2 \mathrm{~A}}$ receptors [60-65].

Augmentation of SSRIs with aripiprazole has been found to be efficacious for the treatment of TRD in multiple randomized, double-blind placebo-controlled studies [60,61,66,67]. Aripiprazole augmentation has shown rapid improvements in Montgomery-Åsberg Depression Rating Scale (MADRS) total scores, as early as the first and second week of treatment with continued improvement throughout the duration of treatment. Aripiprazole augmentation has produced significantly greater remission rates and response rates compared to placebo at the study endpoint, typically 8 weeks. Berman et al. showed a 2-fold greater likelihood of remission with adjunctive aripiprazole compared to placebo [60,66].

Adjunctive aripiprazole has been fairly well tolerated; completion rates with aripiprazole were high and discontinuations due to adverse effects were low, similar to those reported for placebo groups. The most common adverse events associated with aripiprazole included akathisia, headache, fatigue, insomnia, tremor, constipation, and restlessness. Aripiprazole was associated with greater weight gain than placebo though findings were not consistent; two studies showed a significant increase in mean weight gain with adjunctive aripiprazole than with adjunctive placebo $(+2.01 \pm 0.17 \mathrm{~kg} v \mathrm{~s} .+0.34 \pm 0.18$ $\mathrm{kg} ; \mathrm{p}<0.001$ [53]; $+1.47 \pm 0.16 \mathrm{~kg}$ vs. $0.42 \pm 0.17 \mathrm{~kg} ; \mathrm{p}<0.001$; LOCF [61]), whereas Berman et al. found no significant difference in weight gain between adjunctive aripiprazole and adjunctive placebo $(+1.2 \mathrm{~kg}$ vs. $+0.8 \mathrm{~kg} ; \mathrm{p}=0.14$; LOCF) [66]. No adverse effects on prolactin levels were found suggesting that aripiprazole augmentation does not worsen the potential for hyperprolactinemia $[61,68]$. In addition, improvements in sexual function were significantly greater with adjunctive aripiprazole than adjunctive placebo.

Effects on clinical outcomes were significantly improved after adjunctive aripiprazole, as measured using the Sheehan Disability Scale [61]; significant improvement was found on family and social life items but not work items. These improvements with aripiprazole augmentation may be important given the negative impact residual symptoms have on psychosocial function $[69,70]$. It has been reported that reaching full symptomatic remission results in greater improvements in functioning than reaching response without remission or non-response. Full remission is also associated with improved prognosis and enhanced psychosocial functioning and quality of life [71]. Given the multiple replications of improved response rates and remission rates in the adjunctive aripiprazole trials as well as welltolerated safety profile, aripiprazole is well supported as an efficacious augmentation agent for TRD. 
Due to its efficacy and tolerability, aripiprazole became the first atypical antipsychotic to receive U.S. Food and Drug Administration approval for adjunctive treatment of major depressive disorder in 2008 [51] although it is not clear if this approval will be replicated in every other country.

\subsection{Clozapine Augmentation}

Clozapine, has been found to be efficacious in the treatment of refractory schizophrenia, causes less EPS or tardive dyskinesia than typical antipsychotics and does not elevate prolactin levels [72-74]. It has an affinity for dopamine and serotonin receptors [75], which suggests antidepressant potential. Clozapine has shown to be effective in reducing suicidality and suicide attempts in a cohort of neuroleptic-resistant schizophrenic patients [76]; however Sernyak et al. did not find any significant differences in the rate of suicide or accidental death in a large cohort study [77]. Clozapine has been found to have a rare but significant risk of causing agranulocytosis, occurring in 1-2\% of patients who take this particular atypical agent. Clozapine selectively affects precursors of polymorphonuclear leukocytes in bone marrow and has other haematological effects such as leucopenia, neutropenia and eosinophilia. In a meta-analysis comparing clozapine to other atypical antipsychotics for schizophrenia, clozapine showed a tendency for more nausea, fatigue, hypersalivation, and orthostatic dizziness than the other atypical agents. Given the severity of the adverse events associated with clozapine, its use has been limited only to patients who are resistant to or intolerant of other antipsychotic drugs [78].

\subsection{Olanzapine Augmentation}

Preclinical evidence of the atypical antipsychotic, olanzapine, in combination with the SSRI fluoxetine, increases serotonin, norepinephrine, and dopamine in the rat brain [79]. When a combination of olanzapine and fluoxetine was administered, norepinephrine and dopamine levels increased to $242 \%$ and $315 \%$ of baseline values, respectively, values significantly higher than either agent alone. These increases in prefrontal norepinephrine and dopamine levels suggest a plausible neurochemical basis for the synergistic antidepressant effect observed in the clinical trials.

Acute and long-term, double-blind studies of olanzapine alone as well as in combination with fluoxetine have shown mixed results for the treatment of TRD. Thase et al. conducted two parallel, 8week double-blind studies comparing olanzapine monotherapy, fluoxetine monotherapy, and olanzapine/fluoxetine combination [57]. The first study did not find a statistically significant difference in remission rates and response rates between the three treatment options at endpoint; the second study revealed that olanzapine/fluoxetine combination showed significantly greater improvement in efficacy than the other groups. When both studies were pooled, a significant difference in favor of the olanzapine/fluoxetine combination over either agent alone was revealed. Shelton et al. also found superior efficacy for the combination of olanzapine/fluoxetine compared to both monotherapies [54], whereas, a further Shelton et al. study and that of Corya et al. did not find a significant difference between therapies at the endpoint of treatment [11,80]. In these studies, an early and significant improvement in depressive symptoms was shown in the combination groups compared to the monotherapies as early as week 1 and maintained symptom improvement throughout the course of treatment. The monotherapy groups, on the other hand, revealed a steady improvement over the 
8-week trial, and ultimately had similar improvement to the combination group at the endpoint. These studies found that the time to response and remission was significantly shorter for olanzapine/fluoxetine combination treatment than for fluoxetine and olanzapine monotherapies, suggesting a more rapid onset of action. In a long-term, open-label study Corya et al. examined the use of olanzapine/fluoxetine combination over a course of 76 -weeks and found high response rates (53\%) and remission rates $(44 \%)$, and low relapse rates (25\%) at endpoint [81].

Olanzapine and fluoxetine, as well as the olanzapine/fluoxetine combination treatments were relatively well tolerated. The most frequently reported significant adverse events reported in these studies were somnolence, increased appetite, asthenia, weight gain, headache, dry mouth, nausea, anxiety, tremors, and nervousness [11,54,80]. Findings on significant differences between treatments with olanzapine, fluoxetine, and the combination of both agents for treatment emergent adverse events were again, mixed, but reported as mild to moderate. A significant difference among treatment groups in rates of patient discontinuation due to adverse events was found [57,80]. Fewer patients in the fluoxetine monotherapy group discontinued due to adverse events than in the olanzapine and combination groups. The other studies found similar rates of discontinuation due to an adverse event among all treatment groups $[11,54]$. A significantly greater weight gain was observed for those treated with olanzapine (in combination as well as alone) than fluoxetine [11,54,57,80,81]. There were no significant differences in changes in vital signs, laboratory analyses, or EPS in any of the studies with olanzapine. Olanazapine/fluoxetine combination as well as fluoxetine monotherapy showed a statistically significant increase in QTc intervals (cardiac function) than olanzapine alone [16]. Similar to the aripiprazole findings, olanzapine/fluoxetine combination treatment was found to have a significantly greater improvement on the leisure and family items of the Sheehan Disability Scales [57].

In both acute and long-term studies of TRD patients, olanzapine/fluoxetine combination therapy demonstrated a rapid, robust and sustained antidepressant effect and a comparable safety profile to that of its constituent monotherapies. At endpoint, olanzapine/fluoxetine combination did not differ significantly from olanzapine and fluoxetine monotherapies; however, the acute onset of improvement with olanzapine/fluoxetine treatment is likely to have influence on clinical treatment strategies. For instance, the speed of antidepressant effectiveness can be an important factor in treatment choice, particularly when it comes to patients with suicidal ideation [11,54,81].

\subsection{Quetiapine Augmentation}

Quetiapine is approved by the United States Food and Drug Administration (FDA) for schizophrenia, MDD, and bipolar associated manic episodes and depression [82]. The pharmacological profiles of quetiapine are similar to that of the first atypical antipsychotic, clozapine, which antagonizes wide range of receptors including serotonergic $\left(5-\mathrm{HT}_{1 \mathrm{~A}}\right.$ and $\left.5-\mathrm{HT}_{2 \mathrm{~A}}\right)$, dopaminergic $\left(\mathrm{D}_{1}\right.$ and $\left.\mathrm{D}_{2}\right)$, histaminergic $\left(\mathrm{H}_{1}\right)$, and adrenergic ( $\alpha 1$ and $\left.\alpha 2\right)$ receptors [83]. In addition, one of the principal active quetiapine metabolites, norquetiapine, was recently reported to block the human norepinephrine transporter (NET), inhibit norepinephrine reuptake, and exhibit high binding affinity to 5- $\mathrm{HT}_{1 \mathrm{~A}}, \mathrm{H}_{1}$, and $\alpha 1$ receptors [84]. The norepinephrine transporter blockade is a common pharmacologic pathway shared among antidepressants. Also, quetiapine has been reported to have low risk for anticholinergic side effects and low potential for EPS [82]. 
In a randomized, single-blind, placebo-controlled study, patients with MDD and associated anxiety were assigned to either treatment with paroxetine and placebo or paroxetine and quetiapine. After eight weeks, the authors reported significantly decreased HAM-D scores in the combined therapy group compared to the placebo group ( $\mathrm{P}<0.008)$. In terms of anxiety, Hamilton Rating Scale for Anxiety (HAM-A) scores showed a significant improvement with quetiapine $(\mathrm{P}<0.008)$ [85].

Another randomized, double-blind, placebo-controlled study investigated the treatment of MDD and the maintenance of remission of symptoms in 72 patients with MDD. The study compared four groups: paroxetine monotherapy, venlafaxine monotherapy, paroxetine and quetiapine combinedtherapy, and venlafaxine and quetiapine combined-therapy. Overall, improvement in depressive symptoms and the development of remission occurred in the highest frequency in the paroxetine and quetiapine group followed by venlafaxine and quetiapine group, paraxetine monotherapy, and venlafaxine monotherapy in the order of decreasing improvement in depressive symptoms and the development of remission. [86].

In a 6 week, randomized, double-blind, placebo-controlled study, quetiapine at two different doses (150 and $300 \mathrm{mg} /$ day), was augmented in patients with major depressive disorder. Quetiapine augmentation groups at both doses demonstrated a significant improvement in depressive symptoms as quantified by Montgomery-Åsberg Depression Rating Scale (MADRS) and HAM-D total scores. The significant improvement in MADRS was noted as early as week 1 for both quetiapine doses [87]. In contrast to this finding, El-Khalili et al. in their 8-week, multicenter, double-blind, randomized, parallel-group, placebo-controlled study showed significant symptom improvement (MADRS) in week 1 and onward only for the $300 \mathrm{mg}$ /day quetiapine augmentation group; the $150 \mathrm{mg}$ /day quetiapine augmentation group only showed transient efficacy during week 1 [88]. The disagreement in results between the above two studies may be due to the severity of recurrent MDD: $80.6-82.0 \%$ and 90.4-94.4\%, respectively. It is evident to say that $300 \mathrm{mg} /$ day quetiapine augmentation may be more effective than $150 \mathrm{mg}$ /day in patients with treatment resistant major depressive disorder and a high percentage of recurrent MDD. Additionally, Bauer et al. showed a positive association between quetiapine and sleep disturbance; patients who received quetiapine augmentation to ongoing antidepressant treatments demonstrated a beneficial effect on sleep as measured by the HAM-D sleep disturbance item and Pittsburgh Sleep Quality Index (PSQI) scores [87].

Gedge et al. further supported the effect of quetiapine on the alteration in sleep architecture in patients with treatment resistant major depressive disorder [89]. The study rationale was that $90 \%$ of patients with either MDD or bipolar disorder often experience poor sleep quality and quantity [90]. Acute quetiapine treatment (2-4 days) significantly improved sleep architecture involved in total stage 2 sleep, total non-rapid eye movement (non-REM) sleep and the percentage of total sleep time in non-REM sleep. However, the longer-term (21-28 days) effect of quetiapine reverted back to the baseline levels. In terms of depressive symptoms, MADRS total scores significantly improved for both acute and longer-term effect of treatment. Since depression may be associated with decreases in $\mathrm{H}_{1}$ binding [91], the antagonism profile of quetiapine at $\mathrm{H}_{1}$ receptors is likely to complementarily decrease the depressive symptoms via the inhibition of histamine synthesis [89].

Along with sedation, the most commonly reported adverse effects of quetiapine augmentation are somnolence and lethargy in mild to moderate intensity, which is often transient in nature. These adverse effects are presumably due to its strong binding affinity to $\mathrm{H}_{1}$ receptors, followed by 
subsequent down-regulation of histamine synthesis. The transient nature of these side effects implicates rapid tolerability to the actions of quetiapine at $\mathrm{H}_{1}$ receptor [92]. Tolerance to somnolence, sedation, and lethargy has been clinically observed, and the $\mathrm{H}_{1}$ receptor associated adverse effects decrease over time [93]. Thus, patients must be counseled about the likely transient nature of such adverse effects to facilitate the adherence to the quetiapine regimen.

\subsection{Risperidone Augmentation}

Risperidone, developed from the typical antipsychotic, haloperidol, has binding affinity to serotonin $\left(5-\mathrm{HT}_{2}\right)$ and dopamine $\left(\mathrm{D}_{2}\right)$ receptors in the brain [94]. According to Lakoski et al., the antagonist action of risperidone at 5- $\mathrm{HT}_{2}$ receptors amplifies the serotonergic action of SSRIs in the $5-\mathrm{HT}_{2}$ receptors [95]. In contrast to conventional antipsychotics, which have the low 5- $\mathrm{HT}_{2}$ to high $\mathrm{D}_{2}$ ratio profiles [96], risperidone, particularly at low doses, is about 1,000 times more potent in antagonizing 5- $\mathrm{HT}_{2}$ receptors than $\mathrm{D}_{2}$ receptors [97]. Since greater than $80 \%$ occupancy of $\mathrm{D}_{2}$ receptor elicits increasing rates of EPS and tardive dyskinesia, augmentation treatment with low dose of risperidone is more favorable with regards to its safety profile [53]. In addition, numerous studies have suggested risperidone as a first-line augmentation agent for it is comparatively non-sedating, not associated with either weight gain or diabetes, and glucose dysregulation [98,99].

In a double-blind, crossover study, risperidone augmentation treatment showed a significant decline in HAM-D ( $p=0.04)$ and Beck Depression Inventory (BDI) $(p=0.02)$ ratings. Significant improvement in REM sleep, stage 2 sleep, and sleep wakefulness, which was positively associated with the decrease in HAM-D ( $\mathrm{p}=0.02)$ ratings, was reported in the risperidone augmentation group as early as two weeks. These data support the antagonist profile of risperidone involved with potentiation of serotonin and norepinephrine neurotransmission through $5-\mathrm{HT}_{2}$ and $\mathrm{D}_{2}$ receptors blockade, respectively. It is evident to say that the pharmacologic mechanism of risperidone via facilitation of norepinephrine and serotonin neurotransmission lowers REM sleep, which subsequently correlates to improvement in depression [100].

In a double-blind, placebo-controlled study, augmentation with risperidone showed significant improvement in depressive symptoms [101]. Patients who showed an inadequate response to citalopram monotherapy entered an augmentation treatment with risperidone. Those who responded further entered to the longer-term continuation phase either to risperidone or placebo group. It is noteworthy that nonresponders to the original citalopram monotherapy showed marked improvement in symptom reduction during the open-label risperidone augmentation phase and significant delay in relapse rates after the double-blind risperidone continuation (97 days) than placebo continuation (54 days) [55].

Numerous open-label and case reports also have supported the benefits of risperidone augmentation of SSRIs at low dose. Patients who showed suboptimal responses to at least two or more SSRI trials showed acute improvement in mood and anxiety symptom reduction, sleep quality, impulse control, sexual dysfunction, agitation, and response rates and remission rates in as little as 1 week of low dose risperidone augmentation treatment [102-107].

In summary, the 5- $\mathrm{HT}_{2}$ antagonist properties of risperidone in the presence of SSRIs augment the extracellular levels of monoamines. This is likely to be why atypical antipsychotics, such as risperidone, are beneficial in patients with treatment resistant major depressive disorders. The 
published studies suggest that there are short-term benefits when patients with TRD are augmented with risperidone. However, benefits from the longer-term continuation of risperidone may be limited to a subgroup of patients who were fully unresponsive to the original antidepressant monotherapy.

\subsection{Ziprasidone Augmentation}

Ziprasidone was approved by FDA in 2001 as treatment in schizophrenia and mania or mixed states associated with bipolar disorder. Besides its binding affinity for the same receptors as many other atypical antipsychotics including dopaminergic $\left(\mathrm{D}_{2}\right)$, serotonergic $\left(5-\mathrm{HT}_{2 \mathrm{~A}}, 5-\mathrm{HT}_{2} \mathrm{C}\right.$, and $\left.5-\mathrm{HT}_{1 \mathrm{D}}\right)$ receptors, ziprasidone has a singular pharmacological property as a strong 5- $\mathrm{HT}_{1 \mathrm{~A}}$ receptor agonist $[108,109]$. Preclinical studies have suggested that the strong 5-HT $1 \mathrm{~A}$ agonist properties of ziprasidone are associated with release of dopamine in rat prefrontal cortex and inhibition of neuronal uptake of serotonin, norepinephrine, and dopamine [109-111]. Such a receptor binding profile has suggested that ziprasidone may be useful in treating patients with treatment resistant major depressive disorder in conjunction with the ongoing antidepressant regimen. In terms of common adverse effects shared among atypical antipsychotics, ziprasidone is less likely to cause weight gain, elevation in prolactin levels, and EPS than other atypical antipsychotics. Even though FDA labels the use of ziprasidone with a warning due to possible mortality in the elderly with dementia related psychosis and potential for QTc prologation, clinical studies showed a small effect of ziprasidone on the QTc interval between 6 to 10ms, no serious electrocardiographic changes, no severe cardiac adverse events, or tardive dyskinesia [112].

Papakostas et al. demonstrated the potential efficacy of ziprasidone augmentation in patients with treatment resistant major depressive disorder [56]. Twenty patients were enrolled in this open-label trial and experienced $50 \%$ and $25 \%$ response and remission rates, respectively. In addition, data showed considerable improvement after week 1 of treatment. The acute response may be due to dopamine accumulation in the prefrontal cortex. In terms of safety and tolerability profiles, no patient reported any adverse effects or demonstrated a significant increase in QTc. However, 20\% of patients dropped out due to intolerability. In summary, data from ziprasidone augmentation with conventional antidepressants warrants further controlled clinical trials in patients with treatment resistant major depressive disorder [56].

\section{Electroconvulsive Therapy}

If a treatment resistant patient does not show an adequate response to several augmentation treatments, electroconvulsive therapy (ECT) may be advantageous. ECT has long been used as an effective treatment for depression. There are 100,000 patients in the US alone who receive ECT each year, and one million worldwide. In a randomized control trial of patients treated with ECT for depression (both as part of major depression and also bipolar disorder), Kellner et al., found the overall remission rate of 55\% with ECT in the intention to treat analysis [113]. Despite its effectiveness against depression, the use of ECT remains controversial and is not fully trusted by some practitioners and patients [114]. However, according to Semkovska and McLoughlin, in their meta-analysis of 84 studies $(n=2981)$, most cognitive variables showed small to medium improvements six months after ECT [115]. What is noteworthy is that all the impaired cognitive domains (cognitive status 
screening, processing speed, attention/working memory, verbal episodic memory, visual episodic memory, spatial problem solving, executive function and intellectual ability) found in the subacute period (0-3 days) improved after six months and none deteriorated. The subacute transient cognitive impairment among remitters after ECT might be attributable to a sudden modulatory change of brain function impacting on cognition function, which temporarily outweighs the changes associated with the improved depressive symptoms in the subacute period [116]. Considering that there is a positive association of ECT with cognitive improvement in patients with ECT-treated remitted depression, ECT may be clinically favorable for patients with treatment resistant major depressive disorder who have failed augmentation therapies with an atypical antipsychotic.

\section{Conclusions}

The impact of major depressive disorder is severe. The total cost of depression in the British adult population was estimated to be in excess of UK£9 billion in 2000. Cost-effectiveness of pharmacotherapy for depression is affected by dosage practice as well as tailoring of adequate medications. Inadequate medications and dosing reduce effectiveness, which likely impact societal burden due to of working days lost, poor performance and quality of life [117].

Many patients fail their first-line treatments and carry residual symptoms, which is a strong indicator of depression relapse. In order to treat the residual symptoms, older adjunctive methods to first-line antidepressants, including lithium, T3, and typical antipsychotics, have been used. Atypical agents have better pharmacological profiles for the treatment of depression than traditional agents, and have repeatedly shown higher response and remission rates. However, all of these methods are associated with a variable spectrum of efficacy, tolerability and safety profiles. The incidence rate of severe adverse effects commonly associated with these methods of augmentation, such as EPS and tardive dyskinesia, are found to be lower in atypical antipsychotics.

Medication should be prescribed in a personalized manner and with this in mind it is useful to note that these medicines each have a distinct profile of side effects. Drugs with sedative side effects (e.g., olanzapine and quetiapine) may not be the first choice in patients with anergic and hypersomnic symptom profiles; other patients may benefit from these properties, for example many patients with depression related sleep disturbance find the sleep promoting effects beneficial. Such a consideration of the main domains of adverse effects (e.g. extrapyramidal symptoms, weight gain, akathisia, anxiety, nausea, tremor, somnolence, sedation, hyperprolactinemia, headache, etc.) and then an attempt to prescribe in a manner which will best treat the patient's symptoms is to be recommended. Should treatment resistant patients show inadequate response to several atypical antipsychotic augmentation trials, the addition of ECT to the ongoing antidepressant regimen may prove beneficial.

\section{References}

1. World Health Organization. Global Burden of Disease 2004 Update; Health Statistics and Information Department, WHO: Geneva, Switzerland. 2008; http://www.who.int/healthinfo/global_burden_disease/GBD_report_2004update_full.pdf/, accessed on 3 December 2010. 
2. Hasin, D.S.; Goodwin, R.D.; Stinson, F.S.; Grant, B.F. Epidemiology of major depressive disorder: results from the National Epidemiologic Survey on Alcoholism and Related Conditions. Arch. Gen. Psychiatry 2005, 62, 1097-1106.

3. Kessler, R.C.; Berglund, P.; Demier, O.; Jin, R.; Koretz, D.; Merikangas, K.R.; Rush, A.J.; Walters, E.E.; Wang, P.S. National Comorbidity Survey Replication. The epidemiology of major depressive disorder: Results from the National Comorbidity Survey Replication (NCS-R). JAMA 2003, 289, 3095-3105.

4. Diagnostic and Statistical Manual of Mental Disorders, 4th ed.; American Psychiatric Association: Washington, DC, USA, 2000.

5. Chen, Y.W.; Dilsaver, S.C. Lifetime rates of suicide attempts among subjects with bipolar and unipolar disorders relative to subjects with other Axis I disorders. Biol. Psychiatry 1996, 39, 896-899.

6. Bressa, G.M. S-adenosyl-1-methionin (SAMe) as antidepressant: meta-analysis of clinical studies. Acta. Neurol. Scand. 1994, 154, 7-14.

7. Chang, T.; Fava, M. The future of psychopharmacology of depression. J. Clin. Psychiatry 2010, 71, 971-975.

8. Shappert, S.M.; Rechtsteiner, E.A. Ambulatory Medical Care Utilization Estimates for 2006. National Health Statistics Reports, no 8; National Center for Health Statistics: Hyattsville, MD, USA, 2006. http://www.cdc.gov/nchs/data/nhsr/nhsr008.pdf/, accessed on 3 December 2010.

9. Rush, A.J.; Trivedi, M.H.; Wisniewski, S.R.; Nierenberg, A.A.; Stewart, J.W.; Warden, D.; Niederehe, G.; Thase, M.E.; Lavori, P.W.; Lebowitz, B.D.; McGrath, P.J.; Rosenbaum, J.F.; Sackeim, H.A.; Kupfer, D.J.; Luther, J. Fava, M. Acute and longer-term outcomes in depressed outpatients requiring one or several treatment steps: a STAR*D report. Am. J. Psychiatry 2006, 163, 1905-1917.

10. Fava, M.; Davidson, K.G. Definition and epidemiology of treatment-resistant depression. Psychiatr. Clin. North Am. 1996, 19, 179-200.

11. Shelton, R.C.; Williamson, D.J.; Corya, S.A.; Sanger, T.M.; Van Campen L.W.; Case, M.; Briggs, S.D.; Tollefson G.D. Olanzapine/fluoxetine combination for treatment-resistant depression: controlled study of SSRI and nortriptyline resistance. J. Clin. Psychiatry 2005, 66, 1289-1297.

12. Thase, M.E.; Rush, A.J. When at first you don't succeed: sequential strategies for antidepressant nonresponders. J. Clin. Psychiatry 1997, 58 (Suppl. 13), 23-29.

13. Culpepper, L.; Rakel, R.E. The role of atypical antipsychotics in depression in primary care. Primary Care Companion J. Clin. Psychiatry 2003, 5 (Suppl. 3), 33-37.

14. Lambert, G.; Johansson, M.; Agren, H.; Friberg, P. Reduced brain norepinephrine and dopamine release in treatment-refractory depressive illness: evidence in support of the catecholamine hypothesis of mood disorders. Arch. Gen. Psychiatry 2000, 57, 787-793.

15. Maes, M.; De Meester, I.; Scharpe, S.; Desnyder, R.; Ranjan, R.; Meltzer, H.Y. Alterations in plasma dipeptidyl peptidase IV enzyme activity in depression and schizophrenia: effects of antidepressants and antipsychotic drugs. Acta. Psychiatr. Scand. 1996, 93, 1-8.

16. Goodwin, G.; Fleischhacker, W.; Arango, C.; Baumann, P.; Davidson, M.; de Hert, M.; Falkai, P.; Kapur, S.; Leuch, S.; Lich, R.; Naber, D.; O’Keane, V.; Papakostas, G.; Vieta, E.; Zohar, J. Advantages and disadvantages of combination treatment with antipsychotics ECNP Consensus Meeting, March 2008, Nice. PLEFA 2009, 19, 520-532. 
17. Fava, M. Symptoms of Fatigue and Cognitive/Executive Dysfunction in Major Depressive Disorder Before and After Antidepressant Treatment. J. Clin. Psychiatry 2003, 64 (Suppl. 14), 30-34.

18. Trivedi, M.H.; Fava, M.; Marangell, L.B.; Osser, D.N.; Shelton, R.C. Use of treatment algorithms for depression. J. Clin. Psychiatry 2006, 8, 291-298.

19. Trivedi, M.H. Treatment-resistant depression: new therapies on the Horizon. Anna. Clin. Psychiatry 2003, 15, 59-70.

20. Nierenberg, A.A.; Fava, M.; Trivedi, M.H.; Wisniewski, S.R.; Thase, M.E.; McGrath, P.J.; Alpert, J.E.; Warden, D.; Luther, J.F.; Niederehe, G.; Lebowitz, B.; Shores-Wilson, K.; Rush, A.J. Comparison of lithium and T3 augmentation following two failed medication treatments for depression: A STAR*D report. Am. J. Psychiatry 2006, 163, 1519-1530.

21. de la Gandara, J.; Aguera, L.; Rojo, J.E.; Ros, S.; de Pedro, J.M. Use of antidepressant combinations: which, when and why? results of a spanish survey. Acta Psychiat. Scandin. 2005, 112, 32-35.

22. Blier, P.; Haddjeri, N.; Szabo, S.T.; Dong, J. Enhancement of serotoninergic function-A sometimes insufficient cause of antidepressant action. Hum. Psychopharmacol.: Clin. Exper. 2001, 16, 23-27.

23. Papakostas, G.I.; Shelton, R.C.; Smith, J.; Fava, M. Augmentation of antidepressants with atypical antipsychotic medications for treatment-resistant major depressive disorder: a meta-analysis. J. Clin. Psychiatry 2007, 68, 826-831.

24. Ingelman-Sundberg, M. Pharmacogenetics of cytochrome P450 and its applications in drug therapy: the past, present and future. Trends Pharmacol. Sci. 2004, 25, 193-200.

25. Bschor, T.; Lewitzka, U.; Sasse, J.; Adli, M.; Koberle, U.; Bauer, M. Lithium augmentation in treatment-resistant depression: clinical evidence, serotonergic and endocrine mechanisms. Pharmacopsychiatry 2003, 36, 230-234.

26. De Montigny, C. Enhancement of the 5-HT neurotransmission by antidepressant treatments. J.Physiology 1981, 77, 455-461.

27. Katona, C.L. Lithium augmentation in refractory depression. Psychiatric Dev. 1988, 6, 153-171.

28. Lingjaerde, O.; Edlund, A.H.; Gormsen, C.A.; Gottfries, C.G.; Haugstad, A.; Hermann, I.L.; Hollnagel, P.; Makimattila, A.; Rasmussen, K.E.; Remvig, J.; Robak, O.H. The effects of lithium carbonate in combination with tricyclic antidepressants in endogenous depression. A doubleblind, multicenter trial. Acta Psychiat. Scandin. 1974, 50, 233-242.

29. Heninger, G.R.; Heninger, M.D.; Charney, D.S.; Sternberg, D.E. Lithium carbonate augmentation of antidepressant treatment. An effective prescription for treatment-refractory depression. Arch. Gene. Psychiatry 1983, 40, 1335-1342.

30. Schweitzer, I.; Tuckwell, V. Risk of adverse events with the use of augmentation Therapy for the treatment of resistant depression. Drug Saf. 1998, 19, 455-464.

31. Katona, C.L.; Abou-Saleh, M.T.; Harrison, D.A.; Nairac, B.A.; Edwards, D.R.; Lock, T.; Burns, R.A.; Robertson, M.M. Placebo-controlled trial of lithium augmentation of fluoxetine and lofepramine. Br. J. Psychiatry 1995, 166, 80-86. 
32. Baumann, P.; Nil, R.; Souche, A.; Montaldi, S.; Baettig, D.; Lambert, S.; Uehlinger, C.; Kasas, A.; Marlyse, A.; Jonzier-Perey, M. A double-blind, placebo-controlled study of citalopram with and without lithium in the treatment of therapy-resistant depressive patients: a clinical, pharmacokinetic, and pharmacogenetic investigation. J.Clin. Psychopharmacol. 1996, 16, 307-314.

33. Muly, E.C.; McDonald, W.; Steffens, D.; Book, S. Serotonin syndrome produced by a combination of fluoxetine and lithium. Am. J. Psychiatry 1993, 150, 1565

34. Hadley, A.; Cason, M.P. Mania resulting from lithium-fluoxetine combination. Am. J. Psychiatry 1989, 146, 1637-1638.

35. Joffe, R.T.; Singer, W.; Levitt, A.J.; MacDonald, C. A placebo-controlled comparison of lithium and triiodothyronine augmentation of tricyclic antidepressants in unipolar refractory depression. Arch. Gene Psychiatry 1993, 50, 387-393.

36. Stein, G.; Bernadt, M. Double-blind trial of lithium carbonate in tricyclic resistant depression. In Lithium: Inorganic Pharmacology and Psychiatric Use; Birch, N.J., Ed;. IRL Press: Oxford, Washington, DC, USA, 1988; p. 346.

37. Prange, A.J.; Wilson, I.C.; Rabon, A.M.; Lipton, M.A. Enhancement of imipramine antidepressant activity by thyroid hormone. Am. J. Psychiatry 1969, 126, 457-469.

38. Gupta, S.; Masand, P.; Tanquary, J. Thyroid hormone supplementation of fluoxetine in the treatment of major depression. Br. J. Psychiatry 1991, 159, 866-867.

39. Joffe, R.T. Triiodothyronin potentiation of fluoxetine in depressed patients. Can. J. Psychiatry 1992, 37, 48-49.

40. Furukawa, T.A.; Streiner, D.L.; Young, L.T.; Konoshita, Y. Antidepressants plus benzodiazepines for major depression. Cochrane Database Syst. Rev. 2001, 3, CD001026.

41. Mischoulon, D.; Fava, M. Role of S-adenosyl-1-methionine in the treatment of depression: a review of the evidence. Am. J. Clin. Nutr. 2002, 76, 1158S-1161S.

42. Papakostas, G.I.; Michoulon, D.; Shyu, I.; Alpert, J.E.; Fava, M. S-adenosyl methionine (SAMe) augmentation of serotonin reuptake inhibitors for antidepressant nonresponders with major depressive disorder: a double-blind, randomized clinical trial. Am. J. Psychiatry 2010, 167, 942-948.

43. De la Fuente, J.M.; Mendlewicz, J. Carbamazepine addition in tricyclic antidepressant-resistant unipolar depression. Biol. Psychiatry 1992, 32, 369-374.

44. Corrigan, F.M. Sodium valproate augmentation of fluoxetine or fluvoxamine effects. Biol. Psychiatry 1992, 31, 1178-1179.

45. Jacobsen, F.M. Possible augmentation of antidepressant response by buspirone. J. Clin. Psychiatry 1991, 52, 217-220.

46. Bakish, D. Fluoxetine potentiation by buspirone: three case histories. Can. J. Psychiatry 1991, 36, 749-750.

47. Flint, A.J.; Rifat, S.L. The effect of sequential antidepressant treatment on geriatric depression. J. Affective Dis. 1996, 36, 95-105.

48. Bader, G.; Hawley, J.M.; Short, D.D. Venlafaxine augmentation with methylphenidate for treatment-refractory depression: a case report. J. Clin. Psychiatry 1998, 18, 255-256.

49. Lavretsky, H.; Kim, M.D.; Kumar, A.; Reynolds, C.F. Combined treatment with methylphenidate and citalopram for accelerated response in the elderly: an open trial. J. Clin. Psychiatry 2003, 64, 1410-1414. 
50. Nemeroff, C.B. Prevalence and management of treatment-resistant depression. J. Clin. Psychiatry 2007, 68, 17-25.

51. Nelson, J.C.; Papakostas, G.I. Atypical antipsychotic augmentation in major depressive disorder: a meta-analysis of placebo-controlled randomized trials. Am. J. Psychiatry 2009, 166, 980-991.

52. Ray, W.A.; Chung, C.P.; Murray, K.T.; Hall, K.; Stein, M. Atypical antipsychotic drugs and the risk of sudden cardiac death. N. Engl. J. Med. 2009, 360, 225-235.

53. Seeman, P. Atypical antipsychotics: mechanism of action. Can. J. Psychiatry 2002, 47, 27-38.

54. Shelton, R.C.; Tollefson, G.D.; Tohen, M.; Stahl, S.; Gannon, K.S.; Jacobs, T.G.; Buras, W.R.; Bymaster, F.P.; Zhang, W.; Spencer, K.A.; Feldman, P.D.; Meltzer, H.Y. A novel augmentation strategy for treating resistant major depression. Am. J. Psychiatry 2001, 158, 131-134.

55. Rapaport, M.H.; Gharabawi, G.M.; Canuso, C.M.; Mahmoud, R.A.; Keller, M.B.; Bossie, C.A.; Turkoz, I.; Lasser, R.A.; Loescher, A.; Bouhours, P.; Dunbar, F.; Nemeroff, C.B. Effects of Risperidone augmentation in patients with TRD: results of open-label treatment followed by double-blind continuation. Neuropsychopharmacology 2006, 31, 2505-2513.

56. Papakostas, G.I.; Petersen, T.J.; Nierenberg, A.A.; Murakami, J.L.; Alpert, J.E.; Rosenbaum, J.F.; Fava, M. Ziprasidone augmentation of selective serotonin reuptake inhibitors for SSRIs resistant major depressive disorder. J. Clin. Psychiatry 2004, 65, 217-221.

57. Thase, M.E.; Corya, S.A.; Osuntokun, O.; Case, M. Henley, D.B.; Sanger, T.M.; Watson, S.B.; Dubé, S. A randomized, double-blind comparison of olanzapine/fluoxetine combination, olanzapine, and fluoxetine in treatment-resistant major depressive disorder. J. Clin. Psychiatry 2007, 68, 224-236.

58. Kasper, S.; Lerman, M.N.; McQuade, R.D.; Saha, A.; Carson, W.H.; Ali, M.; Archibald, D.; Ingenito, G.; Marcus, R.; Pigott, T. Efficacy and safety of aripiprazole vs haloperidol for longterm maintenance treatment following acute relapse of schizophrenia. Int. J. Neuropsychopharmacol. 2003, 6, 325-337.

59. Vieta, E.; Bourin, M.; Sanchez, R.; Marcus,.R.; Stock, E.; McQuade, R.; Carson, W.; AbouGharbia, N.; Swanink, R.; Iwamoto, T. Aripoprazole Study Group. Effectiveness of aripiprazole v haloperidol in acute bipolar mania: double-blind, randomized, comparative 12-week trial. $\mathrm{Br}$. $\mathrm{J}$. Psychiatry 2005, 187, 235-242.

60. Berman, R.M.; Marcus, R.N.; Swanink, R.; McQuade, R.D.; Carson, W.H.; Corey-Lisle, P.K.; Khan, A. The efficacy and safety of aripiprazole as adjunctive therapy in major depressive disorder: a multicenter, randomized, double-blind, placebo-controlled study. J. Clin. Psychiatry 2007, 68, 843-853.

61. Marcus, R.N.; McQuade, R.D.; Carson, W.H.; Hennicken, D.; Fava, M.; Simon, J.S.; Trivedi, M.H.; Thase, M.E.; Berman, R.M. The efficacy and safety of aripiprazole as adjunctive therapy in major depressive disorder: a second multicenter, randomized, double-bline, placebo-controlled study. J. Clin. Psychopharmacol. 2008, 28, 156-165.

62. Burris, K.D.; Molski, T.F.; Xu, C.; Ryan, E.; Tottori, K.; Kikuch,. T.; Yocca, F.D.; Molinoff, P.B. Aripiprazole, a novel antipsychotic, is a high-affinity partial agonist at human dopamine D2 receptors. J. Pharmacol. Exp. Ther. 2002, 302, 381-389. 
63. Jordan, S.; Koprivica, V.; Chen, R.; Tottori, K.; Kikuchi, T.; Altar, C.A. The antipsychotic aripiprazole is a potent, partial agonist at the human 5-HT (1A) receptor. Eur. J. Pharmacol. 2002, 441, 1137-1140.

64. Shapiro, DA.; Renock, S.; Arrington, E.; Chiodo, L.A.; Liu, L.X.; Sibley, D.R.; Roth, B.L.; Mailman, R. Aripiprazole, a novel atypical antipsychotic drug with a unique and robust pharmacology. Neuropsychopharmacology 2003, 28, 1400-1411.

65. Stark, AD.; Jordan, S.; Allers, KA.; Bertekap, R.L.; Chen, R.; Mistry Kannan, T.; Molski, T.F.; Yocca, F.D.; Sharp, T.; Kikuchi, T.; Burris, K,D. Interaction of the novel antipsychotic aripiprazole with 5-HT $\left(_{1 \mathrm{~A}}\right)$ and 5-HT(2A) receptors: functional receptor-binding and in vivo electrophysiological studies. Psychopharmacology (Ber) 2007; 190, 373-382.

66. Berman, R.M.; Fava, M.; Thase, M.E.; Trivedi, M.H.; Swanink, R.; McQuade, R.D.; Carson, W.H.; Adson, D.; Taylor, L.; Hazel, J.; Marcus, R.N. Aripiprazole Augmentation in major depressive disorder: a double-blind, placebo-controlled study in patients with inadequate response to antidepressants. CNS Spectr. 2009, 14, 197-206.

67. Shefrin, M.; Driscol, H.C.; Lenze, E.J.; Mulsant, B.H.; Pollock, B.G.; Miller, M.D.; Butters, M.A.; Dew, M.A.; Reynolds, C.F., III. Pilot study of augmentation with aripiprazole for incomplete response in late-life depression: getting to remission. J. Clin. Psychiatry 2009, 70, 208-213.

68. Papakostas, G.I.; Miller, K.K.; Petersen T.; Sklarsky, K.G.; Hilliker, S.E.; Klibanski, A.; Fava, M. Serum prolactin levels among outpatients with major depressive disorder during the acute phase of treatment with fluoxetine. J. Clin. Psychiatry 2006, 67, 952-957.

69. Van Londen, L.; Molenaar, R.P.; Goekoop, J.G.; Zwinderman, A.H.; Rooijmans, H.G. Three- to 5-year prospective follow-up of outcome in major depression. Psychol. Med. 1998; 28, 731-735.

70. Judd, L.L.; Akiskal, H.S.; Zeller, P.J.; Paulus, M.; Leon, A.C.; Maser, J.D.; Endicott, J.; Coryell, W.; Kunovac, J.L.; Mueller, T.I.; Rice, J.P.; Keller, M.B. Psychosocial disability during the longterm course of unipolar major depressive disorder. Arch. Gen. Psychiatry 2000, 57, 375-380.

71. Trivedi, M.H.; Corey-Lislie, P.K.; Gui, Z.; Lennox, R.D.; Pikalov, A.; Kim, E. Remission, response without remission, and nonresponse in major depressive disorder: impact on functioning. Int. Clin. Psychopharmacol. 2009, 24, 133-138.

72. Claghorn, J.; Honigfeld, G.; Abuzzahab, F.S., Sr.; Wang, R.; Steinbook, R.; Tuason, V.; Klerman, G. The risks and benefits of clozapine versus chlorpromazine. J. Clin. Psychopharmacol. 1987; 7, 377-384.

73. Lieberman, J.A.; Saltz, B.L.; Johns, C.A.; Pollack, S.; Kane, J.M. Clozapine effects on tardive dyskinesia. Psychopharmacol. Bull. 1989, 25, 57-62.

74. Alvir, J.M.J.; Lieberman, J.A.; Safferman, A.Z.; Schwimmer, J.L.; Schaaf, J.A. Clozapineinduced agranulocytosis. N. Engl. J. Med. 1993, 329, 162-167.

75. Chandrasekaran, P.K. Agranulocytosis monitoring with clozapine: to follow guidelines or to attempt therapeutic controversies. N. Engl. J. Med. 2008, 49, 396-399.

76. Meltzer, H.Y.; Okayli, G. Reduction of suicidality during clozapine treatment of neurolepticresistant schizophrenia: impact on risk-benefit assessment. Am. J. Psychiatry 1995, 152, 183-190.

77. Sernyak, M.J.; Desai, R.; Stolar, M.; Rosenheck, R. Impact of clozapine on completed suicide. Am. J. Psychiatry 2001, 158, 931-937. 
78. Tuunainen, A.; Wahlbeck, K.; Gilbody, S. Newer atypical antipsychotic medication in comparison to clozapine: a systematic review of randomized trials. Schizophrenia Res. 2002, 56, 1-10.

79. Zhang, W.; Perry, K.W.; Wong, D.T.; Potts, B.D.; Bao, J.; Tollefson, G.D.; Bymaster, F.P. Synergistic effects of olanzapine and other antipsychotic agents in combination with fluoxetine on norepinephrine and dopamine release in rat prefrontal cortex. Neuropsychopharmacology 2000, 23, 250-262.

80. Corya, S.A.; Williamson, D.; Sangar, T.M.; Briggs, S.D.; Case, M.; Tollefson, G. A randomized, double-blind comparison of olanzapine/fluoxetine combination, olanzapine, fluoxetine, and venlafaxine in treatment-resistant depression. Depress. Anxiety 2006, 23, 364-372.

81. Corya, S.A.; Anderson, S.W.; Detke, H.C.; Kelly, L.S.; Van Campen, L.E.V.; Sanger, T.M.; Williamson, D.J.; Dubé S. Long-term antidepressant efficacy and safety of olanzapine/fluoxetine combination: a 76-week open-label study. J. Clin. Psychiatry 2003, 64, 1349-1356.

82. Cheer, S.M.; Wagstaff, A.J. Quetiapine. A review of its use in the management of schizophrenia. CNS Drugs 2004, 18, 173-199.

83. Nemeroff, C.B.; Kinkead, B.; Goldstein, J. Quetiapine: preclinical studies pharmacokinetics, drug-interactions, and dosing. J. Clin. Psychiatry 2002, 63 (Suppl. 13), 5-11

84. Jensen, N.H.; Rodriguiz, R.M.; Caron, M.G.; Wetsel, W.C.; Rothman, R.B.; Roth, B.L. Ndesalkylquetiapine, a potent norepinephrine reuptake inhibitor and partial 5-HT1A agonist, as a putative mediator or quetiapine's antidepressant activity. Neuropsychopharmacology 2008, 33, 2303-2312.

85. Yaric, L.I.; Corapcioglu, A.; Kocabasoglu, N.; Erdogan, A.; Koroglu, G.; Yilmaz, D. A prospective randomized single-blind, multicenter trial comparing the efficacy and safety of paroxetine with and without quetiapine therapy in depression associated with anxiety. Int. J. Psychiat. Clin. Practice 2004, 8, 205-211.

86. Hussain, M.Z.; Waheed, W.; Hussain, S.; Chaudhry, Z.A. A comparison of unipolar depression treatment using antidepressants alone versus using antidepressants in combination with quetiapine. Eur. Neuropsychopharmacology 2005, 15 (Suppl. 3), S453-S454

87. Bauer, M.; Pretorius, H.W.; Constant, E.L.; Earley, W.R.; Szamosi, J.; Brecher, M. Extendedrelease quetiapine as adjunct to an antidepressant in patients with major depressive disorder: results of randomized, placebo-controlled, double-blind study. J. Clin. Psychiatry 2009, 70, 540-549.

88. El-Khalili, N.; Joyce, M.; Atkinson, S.; Buynak, R.J.; Datto, C.; Lindgren, P.; Eriksson, H. Extended-release quetiapine fumarate (quetiapine $\mathrm{XR}$ ) as adjunctive therapy in major depressive disorder (MDD) in patients with an inadequate response to ongoing antidepressant treatment: a multicentre, randomized, double-blind, placebo-controlled study. Int. J. Neuropsychopharmacol. 2010, 13, 917-932.

89. Gedge, L.; Lazowski, L.; Murray, D.; Jokic, R.; Milev, R. Effects of quetiapine on sleep architecture in patients with unipolar or bipolar depression. Neuropsychatric Dis. Treatment 2010, 6, 501-508.

90. Riemann, D.; Berger, M. Sleep and depression- results from psychobiological studies: an overview. Biol. Psychol. 2001, 57, 67-103. 
91. Kano, M.; Fukudo, S.; Tashiro, A.; Utsumi, A.; Tamura, D.; Itoh, M.; Iwata, R.; Tashiro, M.; Mochizuki, H.; Funaki, Y.; Kato, M.; Hongo, M.; Yanai, K. Decreased histamine H1 receptor binding in the brain of depressed patients. Eur. J. Neurosci. 2004, 20, 803-810.

92. Goldstein, J.M.; Paulsson, B.; Sweitzer, D.; Zhong, K. A review of the evidence for somnolence with quetiapine treatment. Poster presented at the 158th Annual Meeting of the American Psychiatric Association, Atlanta, GA, USA, 21-26 May, 2005.

93. McIntyre, A.; Gendron, A.; McIntyre, A. Quetiapine adjunct to SSRIs or venlafaxine in patients with major depression, comorbid anxiety, and residual depressive symptoms: a randomized, placebo-controlled pilot study. Depress. Anxiety 2007, 24, 487-494.

94. Frankenburg, F.R. Choices in antipsychotic therapy in schizophrenia. Harvard Rev. Psychiatry 1999, 6, 241-249.

95. Lakoski, J.M.; Aghajanian, G.K. Effects of ketanserin on neuronal responses to serotonin in the prefrontal cortex, lateral geniculate and dorsal raphe nucleus. Neuropharmacology 1985, 24, 265-273.

96. Soloff, P.H. Neuroleptic treatment in the borderline patient: advantage and techniques. J. Clin. Psychiatry 1987, 48, 26-31.

97. Borison, R.L.; Pathiraja, A.P.; Diamond, B.I.; Meibach, R.C. Risperidone: clinical safety and efficacy in schizophrenia. Psychopharmacol. Bull 1992, 28, 213-218.

98. Viner, M.W.; Schroeder, S.; Kamper, P. A practical classification of current atypical antipsychotics. Prim. Psychiat. 2000, 9, 84-88

99. Lindenmayer, J.; Nathan, A.; Smith, R. Hyperglycemia associated with the use of atypical antipsychotics. J. Clin. Psychiatry 2001, 62, 30-38.

100. Sharpley, A.N.; Bhagwagar, Z.; Hafizi, S.; Whale, W.R.; Gijsman, H.J.; Cowan, P.J. Risperidone augmentation decreases rapid eye movement sleep and decreases wake in treatment-resistant depressed patients. J. Clin. Psychiatry 2003, 64, 192-196.

101. Gharabawi, C.; Canuso, G.; Pandina, C.; Bossie, M.; Kujawa C.; Kosik-Gonzalez Risperdone treatment of resistant depression: A double-blind randomized trial. Neuropsychopharmacology 2006, 31, S228.

102. Ostroff, R.B.; Nelson, J.C. Risperidone augmentation of selective serotonin reuptake inhibitors in major depression. J. Clin. Psychiatry 1999, 60, 256-259.

103. Mahmoud, R.A.; Pandina, G.J; Turkoz, I.; Kosik-Gonzales, C.; Canuso, C.M.; Kujawa, M.J.; Gharabawi-Garibaldi, G.M. Risperidone for treatment-refractory major depressive disorder. Anna. Int. Med. 2007, 147, 593-602.

104. O'connor, M.; Silver, H. Adding Risperidone to SSRI improves chronic depression. J. Clin. Psychopharmacol. 1998, 18, 89-91.

105. Kaplan, M. Atypical antipsychotics for treatment of mixed depression and anxiety. J. Clin. Psychiatry 2000, 61, 388-389.

106. Viner, M.W.; Chen, Y.; Bakshi, I.; Kamper, P. Low dose risperidone augmentation of antidepressants in nonpsychotic depressive disorders with suicidal ideation. J. Clin. Psychopharmacol. 2003, 23, 104-106.

107. Hirose, S.; Ashby, C.R. An open pilot study combining Risperidone and a selective serotonin reuptake inhibitor as initial antidepressant therapy. J. Clin. Psychiatry 2002, 63, 733-736. 
108. Sprouse, J.S.; Reynolds, L.S.; Braselton, J.P.; Rollema, H.; Zorn, S.H. Comparison of the novel antipsychotic ziprasidone with clozapine and olanzapine: inhibition of the dorsal raphe firing and the role of 5-HT1A receptor activation. Neuropsychopharmacology 1999, 21, 622-631.

109. Rollema, H.; Lu, Y.; Schmidt, A.W.; Sprouse, J.S.; Zorn, S.H. 5-HT1A receptor activation contributes to ziprasidone-induced dopamine release in the rat prefrontal cortex. Biol. Psychiatry 2000, 48, 229-237.

110. Schmidt, A.W.; Lebel, L.A.; Howard Jr., H.R.; Zorn, S.H. Zirpsidone: a novel antipsychotic agent with a unique human receptor binding profile. Eur. J. Pharmacol. 2001, 425, 197-201.

111. Tatsumi, M.; Jansen, K.; Blakely, R.D.; Richelson, E. Pharmacological profile of neuroleptics at human monoamine transporters. Eur. J. Pharmacol. 1999, 368, 277-283.

112. Glassman, A.H.; Bigger J.T., Jr. Antipsychotic drugs: prolonged QTc interval, torsade de pointes, and sudden death. Am. J. Psychiatry 2001, 158, 1774-1782.

113. Kellner, C.H.; Knapp, R., Husain, M.M.; Rasmussen, K., Sampson, S.; Cullum, M.; McClintock, S.M.; Tobias, K.G., Martino, C.; Mueller, M.; Bailine, S.H.; Fink, M.; Petrides, G., Bifrontal, bitemporal and right unilateral electrode placement in ECT: randomized trial. Br. J. Psychiatry 2010, 196, 226-234.

114. Seo, R.; Young, A. Evaluation of: Objective cognitive performance associated with electroconvulsive therapy for depression: a systematic review and meta-analysis. Biol. Psychiatry 2010, 68, 568-577.

115. Semkovska, M.; McLoughlin, D.M. Objective cognitive performance associated with electroconvulsive therapy for depression: A systematic review and meta-analysis. Biol. Psychiatry 2010, 68, 568-577.

116. Constant, E.L.; Adam, S.; Gillain, B.; Seron, X.; Bruyer, R.; Seghers, A. Effects of sertraline on depressive symptoms and attentional and executive functions in major depression. Depress. Anxiety 2005, 21, 78-89.

117. Vanoli, A.; Lane, C.J.; Harrison, C.; Steen, N.I.; Young, A.H. Adequacy of venlafaxine dose prescribing in major depression and hospital resources implications. J. Psychopharm. 2008, 22, 434-440.

(C) 2010 by the authors; licensee MDPI, Basel, Switzerland. This article is an open access article distributed under the terms and conditions of the Creative Commons Attribution license (http://creativecommons.org/licenses/by/3.0/). 